\title{
Maturação e qualidade de uvas para suco em condições tropicais, nos primeiros ciclos de produção
}

\author{
Thalita Passos Ribeiro(1), Maria Auxiliadora Coêlho de Lima(2) e Ricardo Elesbão Alves ${ }^{(3)}$
}

\begin{abstract}
(1)Universidade Federal Rural do Semi-árido, Avenida Francisco Mota, oo 572 , Bairro Costa e Silva, CEP 59625-900 Mossoró, RN. E-mail: thalita-passos@hotmail.com ${ }^{(2)}$ Embrapa Semiárido, BR 428, Km 152, Zona Rural, Caixa Postal 23, CEP $56302-970$ Petrolina, PE. E-mail: maclima@cpatsa.embrapa.br (3)Embrapa Agroindústria Tropical, Rua Dra. Sara Mesquita, № 2.270, CEP 60511-110 Fortaleza, CE. E-mail: ricardo.alves@embrapa.br
\end{abstract}

\begin{abstract}
Resumo - O objetivo deste trabalho foi caracterizar a maturação e a qualidade das uvas das cultivares Isabel Precoce e BRS Cora, enxertadas sobre 'IAC 572', para a determinação do ponto de colheita. O experimento foi realizado no Vale do Submédio São Francisco, nos ciclos de produção de novembro de 2009 a março de 2010 e de junho a setembro de 2010, em delineamento experimental de blocos ao acaso, com quatro repetições constituídas por cinco cachos. Os cachos foram coletados, periodicamente, a partir do início da maturação, que correspondeu, na 'Isabel Precoce', aos 54, 61, 68, 71, 74 e 77 dias após a frutificação (DAF), no primeiro ciclo, e aos 49, 56, 63, 67, 71, 74 e 77 DAF, no segundo. Na 'BRS Cora', os cachos foram coletados aos 61, 68, 71, 74, 77 e 82 DAF, no primeiro ciclo, e aos 53, 60, 65, 70, 74 e 78 DAF, no segundo. As uvas de 'BRS Cora' são mais ácidas do que as de 'Isabel Precoce'; porém, apresentam maiores teores de sólidos solúveis e de açúcares solúveis. O ponto de colheita da 'Isabel Precoce' ocorreu aos 77 DAF, em ambos os períodos de produção; na 'BRS Cora', ocorreu aos $82 \mathrm{DAF}$, no primeiro semestre, e foi antecipado em quatro dias no segundo.
\end{abstract}

Termos para indexação: Vitis labrusca, BRS Cora, Isabel Precoce, ponto de colheita, produção de sucos, uvas para processamento.

\section{Grape maturation and quality for juice production in tropical conditions in the initial production cycles}

\begin{abstract}
The objective of this work was to characterize the maturation and the grape quality of the cultivars Isabel Precoce and BRS Cora, grafted onto 'IAC 572' rootstock, in order to determine harvest time. The experiment was carried out in the Submédio São Francisco river basin, Brazil, during the production cycles from November 2009 to March 2010 and from June to September 2010, in a randomized complete block design, with four replicates constituted by five bunches. The bunches were periodically collected from the beginning of the maturation, which for 'Isabel Precoce' grapes corresponded to 54, 61, 68, 71, 74, and 77 days after fruit set (DAF), in the first cycle, and to 49, 56, 63, 67, 71, 74, and 77 DAF, in the second one. For 'BRS Cora', the bunches were collected at $61,68,71,74,77$, and $82 \mathrm{DAF}$, in the first cycle, and at 53,60,65, 70, 74, and $78 \mathrm{DAF}$, in the second cycle. The 'BRS Cora' grapes are more acid than the 'Isabel Precoce' ones; however, they show the highest contents of soluble solids and soluble sugar. The harvest time for 'Isabel Precoce' grapes occurred at $77 \mathrm{DAF}$ in both productive periods; for 'BRS Cora' grapes, it occurred at $82 \mathrm{DAF}$, in the first semester, and it was anticipated by four days in the second one.
\end{abstract}

Index terms: Vitis labrusca, BRS Cora, Isabel Precoce, harvest time, juice production, processing grapes.

\section{Introdução}

A área colhida de uva no Brasil, em 2010, foi de 79.970 ha, dos quais 59.732 ha estão na Região Sul e 9.969 ha na Região Nordeste (Levantamento sistemático da produção agrícola, 2011). O Rio Grande do Sul destaca-se como o maior produtor brasileiro, pois explora, principalmente, cultivares destinadas à elaboração de vinhos e de sucos, por meio de práticas apropriadas ao cultivo em condições de clima temperado. Na Região Nordeste, em razão das condições ambientais, com altas temperaturas na maior parte do ano, desenvolve-se uma viticultura diferenciada, para produção de uvas de mesa (Camargo et al., 2008). No entanto, a relevância dessa região para viticultura dá-se, principalmente, pelo direcionamento da produção para o mercado externo, já que ela responde pela quase totalidade do volume de uva exportado pelo país que, segundo o Instituto Brasileiro de Frutas (2011), alcançou 60.805 toneladas e rendeu cerca de 136 milhões de dólares, em 2010. 
No Vale do Submédio do São Francisco, o cultivo de uvas de mesa começa a dar seus primeiros sinais de saturação, principalmente em tempos de câmbio desfavorável às vendas no exterior. Com a menor lucratividade, a agroindústria passa a ser uma possibilidade de agregar valor a um produto mais barato, como é a uva que se destina à elaboração de suco. Sua produção dispensa algumas práticas mais tecnificadas de manejo cultural, o que reduz os custos e demanda menor investimento (Giovannini, 2005). Assim, a região procura ampliar sua base vitícola, despontando na produção de uvas destinadas à elaboração de vinhos finos e, ultimamente, de uvas para suco. Neste segmento, as poucas áreas são implantadas principalmente com a cultivar Isabel Precoce, que tem resultado em produtos de boa qualidade.

Estudos têm sido realizados para caracterizar as uvas destinadas à elaboração de sucos, mesmo em regiões com aptidão produtiva natural, mas com novas cultivares de maior produtividade e qualidade do suco. Sato et al. (2008), em estudo na Região Norte do Paraná para avaliação de características físico-químicas e de produção com cultivares de videira enxertadas sobre diferentes porta-enxertos, observaram que a cultivar Isabel destacou-se pelo alto teor de sólidos solúveis e melhor desempenho para a características fisícas e produtivas.

Na Região Norte Fluminense, no Estado do Rio de Janeiro, estudos sobre a caracterização fenológica das cultivares de videira Isabel, Romana, Kyoho, Moscatel de Hamburgo, Roberta e Niágara Rosada indicaram a primeira como a mais tardia, com ciclo médio de 124 dias (Silva et al., 2008). Segundo Orlando et al. (2008), na região de Jundiaí, SP, a cultivar Syrah, sobre os porta-enxertos IAC 572 e IAC 571-6, apresentaram alto potencial para cultivo. Para as condições do Municipio de Caldas, no Estado de Minas Gerais, as cultivares Niágara Rosada e Folha de Figo apresentaram elevada produção sobre 'IAC 572', porém com prejuízo para a qualidade das bagas, que se caracterizaram pela maior acidez titulável e pelos menores teores de antocianinas e de compostos fenólicos (Mota et al., 2009).

Para as condições do Semiárido, no entanto, ainda há a necessidade de estudos que forneçam informações sobre técnicas de manejo, cultivares adaptadas ao clima quente e qualidade das uvas produzidas - à semelhança das primeiras iniciativas de avaliação de cultivares para elaboração de vinhos.

O objetivo deste estudo foi caracterizar a maturação e a qualidade das uvas das cultivares Isabel Precoce e BRS Cora, enxertadas sobre 'IAC 572', para a determinação do ponto de colheita.

\section{Material e Métodos}

A área foi instalada no Campo Experimental de Bebedouro, da Embrapa Semiárido ( $\left.09^{\circ} 09^{\prime} \mathrm{S}, 40^{\circ} 22^{\prime} \mathrm{W}\right)$, no Município de Petrolina, PE, em 26 de fevereiro de 2007. As uvas das cultivares Isabel Precoce e BRS Cora foram conduzidas em sistema de latada, em espaçamento $4 \times 2 \mathrm{~m}$, com seis plantas por parcela, sobre o porta-enxerto 'IAC 572' e sob irrigação por microaspersão.

Foram avaliados dois ciclos de produção, que tiveram início a partir da segunda e terceira podas de produção, realizadas em 25 de novembro de 2009 e 11 de junho de 2010, respectivamente. A frutificação ocorreu em 17 de dezembro de 2009, no primeiro ciclo, e 12 de julho de 2010, no segundo. Do início da maturação reconhecida pela mudança de cor das bagas e início de amaciamento da polpa - até a colheita para a elaboração dos sucos, foram coletados cinco cachos de uvas de cada cultivar por parcela. Para 'Isabel Precoce', as coletas foram aos 54, 61, 68, 71, 74 e 77 dias após a frutificação (DAF), no primeiro ciclo avaliado, e aos 49, 56, 63, 67, 71, 74 e 77 DAF, no segundo ciclo. Para 'BRS Cora', os cachos foram coletados aos $61,68,71$, 74, 77 e 82 DAF, no primeiro ciclo, e aos 53, 60, 65, 70, 74 e 78 DAF, no segundo ciclo.

Os dados meteorológicos no local do estudo, no período correspondente aos dois ciclos de avaliação, estão apresentados na Tabela 1. O Campo Experimental de Bebedouro, em 2010, apresentou temperatura média anual de $26,3^{\circ} \mathrm{C}$, umidade relativa do ar em torno de $71 \%$ e precipitação de $549,2 \mathrm{~mm}$ (médias anuais da estação agrometeorológica de Bebedouro, 2012).

Os cachos colhidos foram avaliados no Laboratório de Fisiologia Pós-Colheita da Embrapa Semiárido, quanto aos atributos físicos, físico-químicos e químicos relativos à qualidade da uva. As variáveis analisadas foram: massa de matéria fresca do cacho, cor da casca, resistência da baga à compressão, acidez titulável, sólidos solúveis e açúcares solúveis totais. 
A massa de matéria fresca do cacho (g) foi determinada por meio do valor médio da pesagem de cinco cachos recém-colhidos, em balança semianalítica modelo VI 2400, (Acculab, Florida, EUA). A cor da casca foi avaliada por meio de reflectômetro digital Colortec PCM, (Accuracy Microsensors INC., Pittsford, NY, EUA), com leitura direta e única, na região equatorial, em 30 bagas representativas, colhidas uniformemente das regiões superior, mediana e inferior dos cinco cachos que compunham a amostra, segundo os atributos de luminosidade (L), a* e b*. Estes atributos representam uma escala de componentes da cor, em que os pontos estão em um espaço tridimensional, de forma que, em conjunto, correspondem às cores como são vistas pelo olho humano. Este espaço é representado pelos eixos de L (cujos valores variam de 100, que representa a cor branca, a 0 , que corresponde à cor preta), e pelas coordenadas cromáticas a* (valores positivos representam a cor vermelha, e os negativos a cor verde) e b* (valores positivos representam a cor amarela, e os negativos a cor azul) (Miguel et al., 2009).

Na determinação da resistência da baga à compressão, utilizou-se texturômetro digital Extralab TA.XT.Plus (Stable Micro Systems, Surrey, Reino Unido), dotado de placa de pressão $\mathrm{P} / 75$, pelo qual se mediu a força necessária, em g, para promover compressão de $20 \%$ do volume da baga (Steffens et al., 2009). A pressão foi exercida sobre a baga disposta longitudinalmente. Para as leituras, foram usadas 20 bagas por parcela, separadas uniformemente dos cinco cachos que compunham a unidade experimental, por meio de corte na região acima do pedicelo.

A acidez titulável ( $\mathrm{g}$ de ácido tartárico por $100 \mathrm{~mL}$ ) foi determinada por titulação com solução de $\mathrm{NaOH} 0,1 \mathrm{~N}$ (AOAC International, 1992). O teor de sólidos solúveis ( ${ }^{\circ}$ Brix) foi obtido por leitura direta do suco extraído da polpa, em refratômetro digital Abbe Marck II (Reichert Jung, Depew, NY, EUA) (AOAC International, 1992). Os teores de açúcares solúveis totais ( $\mathrm{g}$ por $100 \mathrm{~g}$ ) foram dosados com o reagente antrona, com leitura realizada em espectrofotômetro UV-Vis 482 (Femto, São Paulo, SP, Brasil) a $620 \mathrm{~nm}$ (Yemn \& Willis, 1954).

$\mathrm{O}$ experimento foi realizado em delineamento experimental de blocos ao acaso, com quatro repetições, constituídas por cinco cachos, coletados periodicamente de cinco plantas de cada parcela no campo. Em razão das diferenças entre as duas cultivares, em relação ao início e à duração da maturação, os dados das uvas 'Isabel Precoce' e 'BRS Cora' foram submetidos à análise estatística separadamente. Da mesma forma, os dados relativos a cada uma das safras também foram submetidos a análises estatísticas independentes.

No estudo, os tratamentos corresponderam à idade das bagas ou ao número de dias após a frutificação (DAF), em cada ciclo e para cada cultivar.

Os dados foram submetidos à análise de variância e, quando significativos, foram submetidos à análise de regressão por meio do programa Sisvar versão 4.3. Para a análise de regressão, foram admitidas equações polinomiais de até $3^{3}$ grau e com coeficientes de determinação superiores a $70 \%$.

Tabela 1. Dados meteorológicos mensais do Campo Experimental de Bebedouro, da Embrapa Semiárido, referentes aos dois ciclos produtivos avaliados, desde a poda até a colheita das videiras 'Isabel Precoce' e 'BRS Cora'.

\begin{tabular}{|c|c|c|c|c|c|c|c|c|}
\hline \multirow[t]{2}{*}{ Período } & \multicolumn{3}{|c|}{ Temperatura $\left({ }^{\circ} \mathrm{C}\right)$} & \multirow{2}{*}{$\begin{array}{c}\text { Umidade } \\
\text { relativa }(\%)\end{array}$} & \multirow{2}{*}{$\begin{array}{c}\text { Insolação } \\
\text { (h) }\end{array}$} & \multirow{2}{*}{$\begin{array}{l}\text { Radiação } \\
\left(\text { Ly dia }^{-1}\right)\end{array}$} & \multirow{2}{*}{ Evaporação } & \multirow{2}{*}{ Precipitação } \\
\hline & Média & Máxima & Mínima & & & & & \\
\hline & \multicolumn{8}{|c|}{ Primeiro ciclo } \\
\hline 25 a $30 / 11 / 2009$ & 27,4 & 34,8 & 22,0 & 55 & 9,7 & 496,4 & 9,0 & 0,0 \\
\hline Dezembro/2009 & 27,4 & 33,7 & 23,0 & 60 & 5,4 & 447,6 & 7,3 & 49,0 \\
\hline Janeiro/2010 & 27,1 & 33,8 & 22,4 & 61 & 6,9 & 360,5 & 7,8 & 8,9 \\
\hline Fevereiro/2010 & 28,1 & 34,8 & 23,5 & 59 & 5,9 & 350,9 & 8,9 & 77,5 \\
\hline 01 a 09/03/2010 & 28,0 & 35,0 & 24,2 & 70 & 6,2 & 343,1 & 7,2 & 2,6 \\
\hline \multirow[t]{2}{*}{ Média } & 27,6 & 34,4 & 23,0 & 61 & 6,8 & 399,7 & 8,0 & 27,6 \\
\hline & \multicolumn{8}{|c|}{ Segundo ciclo } \\
\hline 11 a $30 / 06 / 2010$ & 24,1 & 29,7 & 19,5 & 65 & 3,5 & 257,4 & 5,4 & 0,1 \\
\hline Julho/2010 & 23,7 & 29,7 & 19,0 & 66 & 4,7 & 287,6 & 5,6 & 12,0 \\
\hline Agosto/2010 & 24,4 & 31,1 & 18,9 & 56 & 7,6 & 333,9 & 8,0 & 0,0 \\
\hline 01 a 28/09/2010 & 25,7 & 32,0 & 20,4 & 52 & 7,0 & 307,5 & 8,8 & 0,1 \\
\hline Média & 24,5 & 30,6 & 19,4 & 60 & 5,7 & 296,6 & 7,0 & 3,1 \\
\hline
\end{tabular}

Fonte: Médias anuais da estação agrometeorológica de Bebedouro (2010), Petrolina, PE. 


\section{Resultados e Discussão}

Houve efeito significativo da variável número de dias após a frutificação, sobre a cor da baga (atributos L, a* e $b^{*}$ ) e sobre sua resistência à compressão, analisadas em cada cultivar nas duas safras. Quanto à massa de matéria fresca, os cachos de 'Isabel Precoce', produzidos no segundo semestre de 2010, não apresentaram variação significativa ao longo da maturação, diferentemente das uvas dessa cultivar no primeiro ciclo de produção de 2010 e da cultivar BRS Cora.

No primeiro ciclo de 2010, houve aumento da massa de matéria fresca do cacho da cultivar Isabel Precoce, de 130,75 g no início da maturação (54 DAF) a 151,45 g na última avaliação (77 DAF) (Figura 1). Não houve efeito significativo da idade da baga, por ocasião das coletas durante a maturação, sobre a massa de matéria fresca dos cachos dessa cultivar no segundo ciclo de 2010.

Para 'BRS Cora', no primeiro ciclo de 2010, observou-se tendência de incremento na massa de matéria fresca do cacho, ainda que tenham ocorrido variações nas respostas entre as amostras avaliadas em cada data (Figura 1). Este comportamento pode ter sido decorrente de aspectos relacionados à amostragem, em cada coleta de cachos para avaliação, uma vez que o cacho já atingira tamanho considerável (em torno de $120 \mathrm{~g}$ ), no início da maturação. Segundo Camargo \& Maia (2004), o cacho dessa cultivar pesa em torno de $150 \mathrm{~g}$, é cilindro-cônico, alado, solto e com pedúnculo médio. Por ocasião da colheita no primeiro ciclo de produção, os cachos da cultivar
BRS Cora, atingiram massa de matéria fresca média de cerca de 126 g. Porém, no segundo ciclo de 2010, a massa dos cachos dessa cultivar, que foi de $104,91 \mathrm{~g}$ aos 53 DAF, diminuiu para 97,28 e 75,52 g, aos 74 e 78 DAF, respectivamente (Figura 1). As causas podem estar associadas ao estresse hídrico praticado nessa fase. Esse estresse visa concentrar os açúcares e outros compostos que favorecem a elaboração de sucos de melhor qualidade; porém, neste estudo, promoveu sinais visíveis de murcha nas bagas.

Os resultados concordam com informações obtidas da literatura. No estudo realizado por Sato et al. (2008), na região Norte do Paraná, a massa dos cachos da uva 'Isabel' foi de $125,1 \mathrm{~g}$, tendo-se destacado como superior à de outras cultivares para elaboração de suco, como a BRS Rúbea, cuja massa foi de apenas 83,1 g. Sobre o porta-enxerto 'IAC-572', a uva 'Isabel', cultivada na mesma região, apresentou massa dos cachos de 155,0 g (Sato et al., 2009). Os autores ressaltaram a versatilidade desse porta-enxerto, que adapta-se a regiões de clima temperado e tropical.

Quanto à resistência da baga à compressão, os valores foram elevados no início da maturação e diminuíram progressivamente até a estabilização nas últimas avaliações (Figura 1). Isso pôde ser observado em ambas as cultivares estudadas, principalmente no primeiro ciclo produtivo de 2010. Os valores mensurados nas bagas das uvas 'BRS Cora', produzidas no segundo ciclo, apresentaram resposta irregular, tendo-se observado, após diminuição na segunda data de avaliação, aumento na resistência da baga à compressão, provavelmente em virtude da murcha

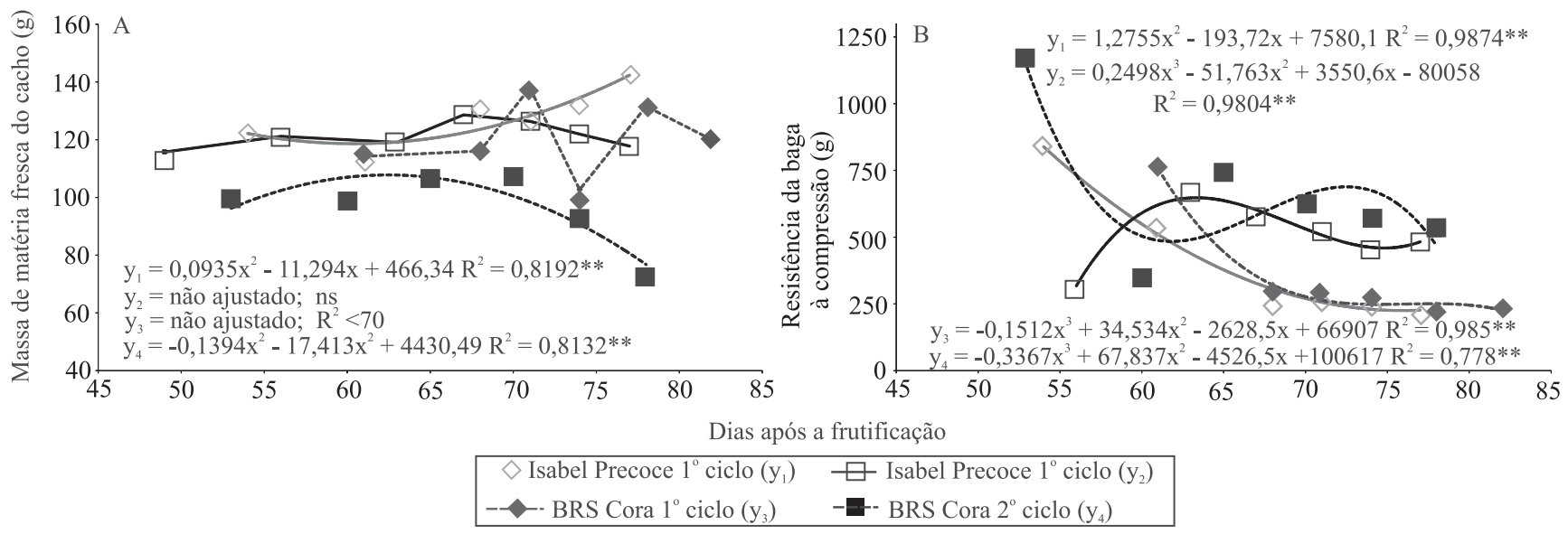

Figura 1. Massa de matéria fresca do cacho (A) e resistência da baga à compressão (B), nas uvas 'Isabel Precoce' e 'BRS Cora', avaliadas durante a maturação dos frutos, em dois ciclos de produção sucessivos no ano de 2010. 
observada ao final da maturação. A murcha, segundo Cia et al. (2010), torna a baga mais elástica e, em consequência, impõe maior resistência à perfuração, da mesma forma que retarda o retorno do tecido ao formato normal após sofrer uma deformação.

A importância de se conhecer a resistência da baga à compressão está associada à facilidade de execução da etapa de esmagamento, que constitui a primeira separação entre o suco e as partes sólidas (casca e semente) durante o processamento (Soares et al., 2008; Manfroi, 2009). A menor resistência da baga é indicativa de amaciamento dos tecidos da polpa que, por conseguinte, desprendem-se mais facilmente do pedicelo. Essa condição permite maior rendimento na operação do desengace, que antecede a maceração.

Ao final da maturação, as bagas de 'Isabel Precoce' apresentaram resistência à compressão de 220,73 e 482,31 g, para o primeiro e o segundo ciclo, respectivamente. Na 'BRS Cora', os valores foram, na mesma ordem, de 236,98 e 518,59 g (Figura 1). Por se tratar de uvas para processamento, os valores são considerados adequados e, caracteristicamente, são inferiores aos observados em uvas para consumo da fruta fresca (Miguel et al., 2009; Mascarenhas et al., 2010), nas quais a logística de comercialização e as exigências de mercado requerem maior firmeza das bagas.

Por sua vez, as diferenças observadas para resistência da baga à compressão, entre os ciclos avaliados (Figura 1), podem estar relacionadas à maior atividade metabólica sob temperaturas mais elevadas (Lima \& Choudhury, 2007). Sugere-se que as diferenças de cerca de $4,0^{\circ} \mathrm{C}$ na temperatura do ar, $1 \mathrm{~h}$ de insolação, associada à maior amplitude entre os valores, e de 100 ly dia ${ }^{-1}$ de radiação entre os ciclos (Tabela 1) estimulam os processos fisiológicos que promovem o amaciamento dos tecidos, em especial a degradação de compostos da parede celular por ação enzimática.

A cor é um componente de qualidade importante, tanto para produtos in natura quanto para processados. No caso de uvas destinadas à elaboração de suco, a cor das bagas influencia de maneira determinante o produto final, que apresenta características distintas quanto à uniformidade e à intensidade de cor, conforme a cultivar, as condições ambientais dominantes durante o ciclo produtivo e as práticas adotadas no manejo da cultura (Guerra, 2003).
Para a luminosidade da casca, quanto mais próximo de 100 forem os valores, maior será a reflexão difusa. $\mathrm{Na}$ avaliação das uvas cultivadas no primeiro semestre de 2010, a 'Isabel Precoce' apresentou maior brilho no momento da colheita que a BRS Cora, com valores de 38,41 e 37,79, respectivamente (Figura 2). As uvas cultivadas no segundo semestre desse mesmo ano apresentaram, na colheita, valores de L da casca de 23,76
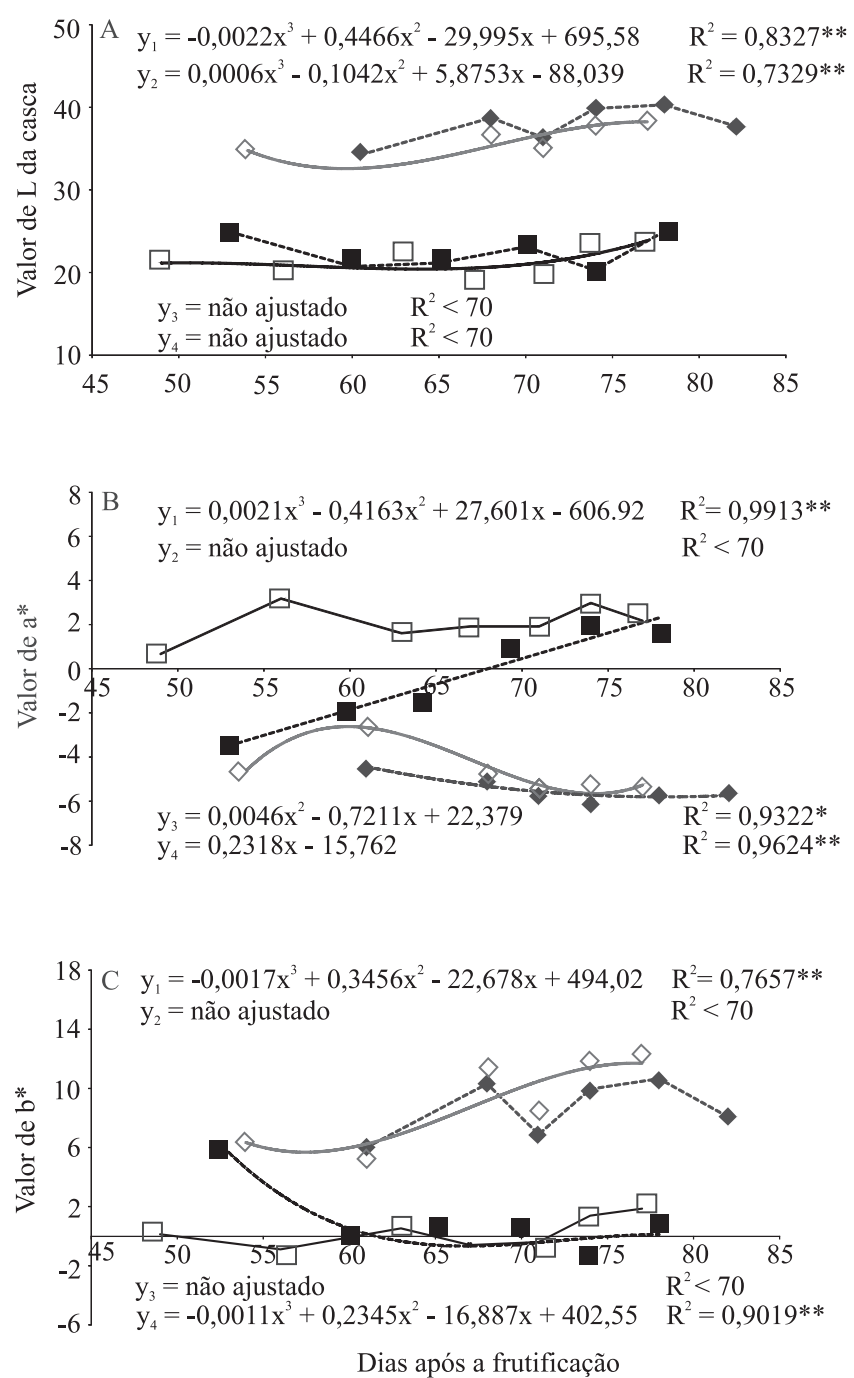

$\diamond$ BRS Isabel Precoce $1^{\circ}$ ciclo $\left(\mathrm{y}_{1}\right)$ BRS Isabel Precoce $2^{\circ}$ ciclo $\left(\mathrm{y}_{2}\right) \quad \cdots-{ }^{-\cdots}$ BRS Cora $2^{\circ}$ ciclo $\left(\mathrm{y}_{4}\right)$

Figura 2. Cor da casca, definida pelos atributos luminosidade (A), a* (B) e b* (C), em uvas 'Isabel Precoce' e 'BRS Cora', avaliadas durante a maturação dos frutos, em dois ciclos de produção sucessivos no ano de 2010. 
e 24,98, respectivamente. Menores valores de $\mathrm{L}$ podem ser decorrentes de maior quantidade de cera epicuticular (pruína) sobre as bagas, em resposta, provavelmente, à menor temperatura durante o segundo ciclo produtivo. A importância do valor $L$ da casca é maior para cultivares destinadas ao consumo da fruta fresca, em virtude da valorização da aparência que atrai o consumidor. Porém, este não é o caso das uvas destinadas apenas ao processamento, cuja casca se torna resíduo. Nestas, outros componentes da cor têm importância. Além disso, para uvas como 'Isabel Precoce', que também são usadas frescas, o conjunto das variáveis deve ser observado.

Ao contrário da resposta observada para L, os valores para $\mathrm{a}^{*}$ foram mais elevados nas bagas dos cachos colhidos no segundo ciclo de produção de 2010 (Figura 2). Assim, essas bagas apresentaram coloração vermelha mais intensa. Isso, provavelmente, resultou da menor insolação (h) no segundo semestre de 2010, ou das altas temperaturas máximas registradas no primeiro ciclo de 2010 (Tabela 1), pois estas características influenciam a síntese de antocianinas e a degradação da clorofila. Segundo Lima \& Choudhury (2007), a intensidade da coloração depende inicialmente de características varietais, mas é influenciada por fatores ambientais como luminosidade, que estimula a síntese de antocianinas, e temperaturas elevadas, que inibem a formação da cor.

Para o atributo $b^{*}$, os valores observados estiveram no eixo positivo, o que indica a presença, ainda que discreta, de pigmentos amarelos e a ausência de pigmentação azul (Figura 2). Nesse caso, como no atributo a*, o componente com mais influência nos resultados foi a safra (período do ano). É provável que as maiores temperaturas no primeiro ciclo tenham estimulado a degradação de clorofila na casca e exposto os pigmentos amarelos. A síntese desses pigmentos também pode ter sido favorecida, em paralelo à degradação de clorofila.

Os atributos a* e b* são importantes para as uvas destinadas à elaboração de suco, pois a cor das bagas contribui preponderantemente para a coloração final do produto. As cultivares de uva com coloração vermelha mais intensa, com maiores valores de a*, apresentam correlação positiva com o conteúdo de antocianinas e, consequentemente, com o de polifenóis totais dos sucos elaborados (Celotti \& De Prati, 2005).

Para as variáveis acidez titulável (AT), teor de sólidos solúveis (SS) e teor de açúcares solúveis totais (AST), foram observadas diferenças significativas da idade das bagas nas cultivares Isabel Precoce e BRS Cora, nas duas safras de produção de 2010.

As uvas apresentam decréscimo característico na AT durante a maturação. No presente estudo, essa resposta foi confirmada, e as uvas da cultivar BRS Cora mostraram-se mais ácidas do que as da Isabel Precoce, em ambos os ciclos de produção (Figura 3). Segundo
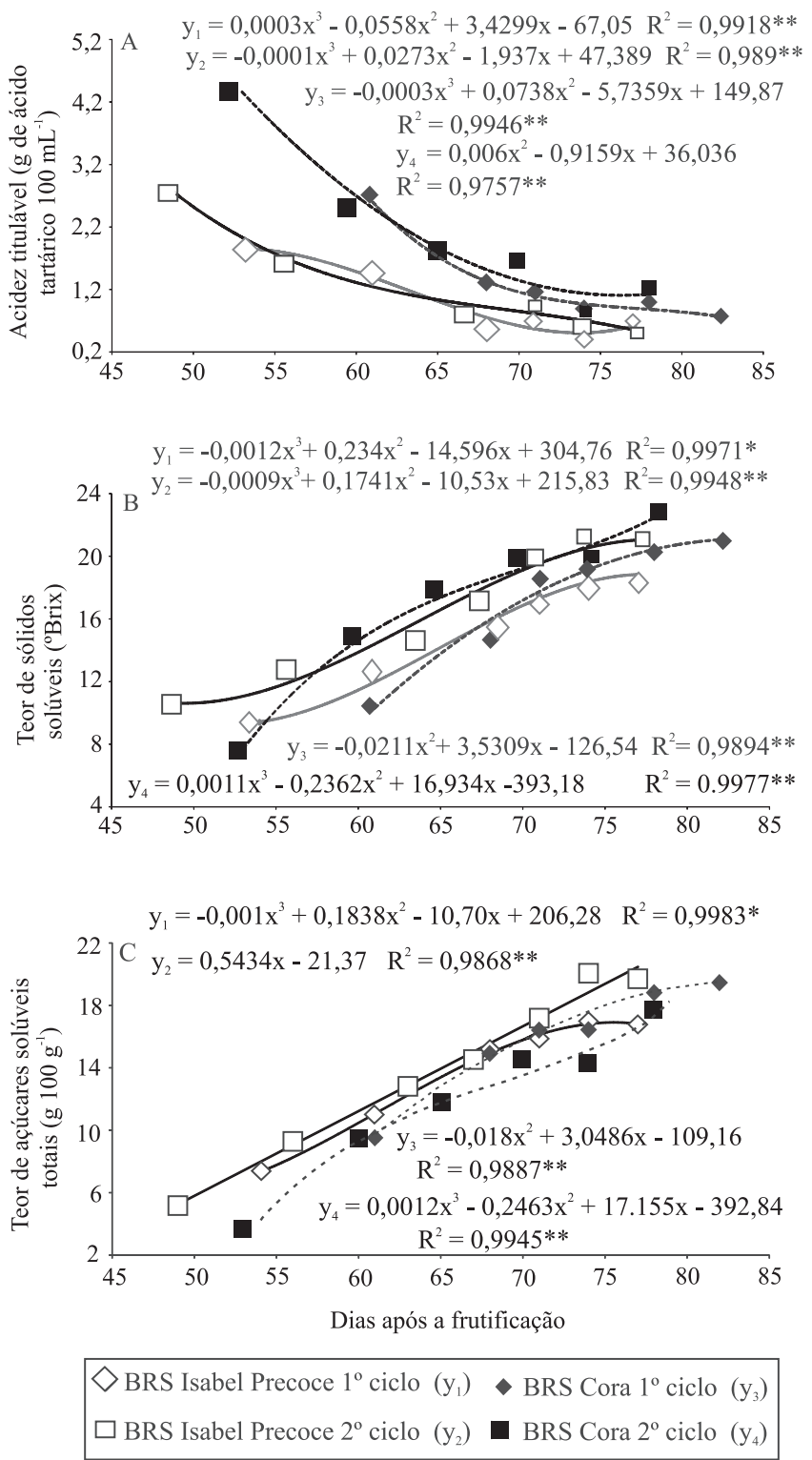

Figura 3. Acidez titulável (A), teor de sólidos solúveis (B) e açúcares solúveis totais (C) de uvas 'Isabel Precoce' e 'BRS Cora', avaliadas durante a maturação dos frutos, em dois ciclos de produção sucessivos no ano de 2010. 
Guerra (2003), as uvas destinadas à elaboração de suco devem apresentar AT entre 0,5 e 0,9 g de ácido tartárico por $100 \mathrm{~mL}$, para que o produto final seja de boa qualidade.

No caso da uva 'Isabel Precoce', independentemente do período de produção, aos $77 \mathrm{DAF}$, a AT atingiu valores próximos a $0,6 \mathrm{~g}$ de ácido tartárico por $100 \mathrm{~mL}$. A variável AT das uvas da cultivar BRS Cora, no momento da colheita, foi de $0,8 \mathrm{~g}$ de ácido tartárico por $100 \mathrm{~mL}$, no primeiro ciclo de 2010 , e de $1,23 \mathrm{~g}$ de ácido tartárico por $100 \mathrm{~mL}$, no segundo. Entretanto, salienta-se que, no segundo semestre de 2010, aos $74 \mathrm{DAF}$, a AT diminuiu a $0,82 \mathrm{~g}$ de ácido tartárico por $100 \mathrm{~mL}$, e houve aumento posterior. Isso pode ter ocorrido em virtude dos sinais de murcha das bagas, já comentado, que teria acarretado maior concentração das substâncias presentes na polpa.

Pereira et al. (2008) observaram AT de 1,2, 0,9, 1,3, 1,7 e 0,8 g de ácido tartárico por $100 \mathrm{~mL}$, na colheita, das cultivares Folha de Figo, Alwood, Concord, BRS Rúbea e Isabel, respectivamente, produzidas no sul de Minas Gerais. Também em cultivos no Estado de Minas Gerais, a AT encontrada por ocasião da colheita das uvas das cultivares Niágara Rosada, Folha de Figo, Syrah, Merlot e Moscato Embrapa foi de 0,9, 0,7, 1,1,1,1 e 1,0 g de ácido tartárico por $100 \mathrm{~mL}$, respectivamente (Abe et al., 2007). Para a cultivar Patrícia, Silva et al. (2008) observaram 0,8 g de ácido tartárico por $100 \mathrm{~mL}$, também no momento da colheita. Na maioria dessas cultivares, a AT foi superior à faixa indicada por Guerra (2003) para a elaboração de sucos de qualidade. No presente estudo, a uva 'BRS Cora' apresentou, na colheita do ciclo de setembro de 2010, AT acima da faixa recomendada. Porém, nessas situações, deve-se avaliar seu uso em misturas com outras cultivares, com o fim de equilibrar sucos com acidez reduzida.

Houve aumento progressivo do teor de SS durante a maturação das uvas 'Isabel Precoce' e 'BRS Cora', nos dois ciclos de produção (Figura 3). As uvas produzidas no segundo semestre de 2010 apresentaram maior teor de SS, tendo-se observado valores de 21,0 ${ }^{\circ}$ Brix, na 'Isabel Precoce', e de 22,6 Brix, na 'BRS Cora'. O teor de SS depende da cultivar, do tamanho da baga, da produção da planta e das condições climáticas. Podem ocorrer, ainda, variações em consequência de perda de água, que concentra os solutos presentes, ou de aumento da absorção de água após chuva ou irrigação (Lima
\& Choudhury, 2007). No presente estudo, o maior índice pluvial durante o primeiro ciclo de produção pode ter contribuído para que as uvas tivessem menor teor de SS. A queda no teor de SS também pode ser atribuída à perda de solutos, decorrente do transporte destes das bagas para as outras partes da planta, ou de alta atividade respiratória e transpiratória, associada a temperaturas mais altas. Além disso, a ocorrência de murcha nas bagas de 'BRS Cora' colhidas no segundo semestre pode explicar o incremento final no teor de SS.

Em estudos realizados em condições de temperatura amena e maior umidade relativa do ar, como no sul de Minas Gerais e no norte do Paraná, Pereira et al. (2008) e Sato et al. (2008), respectivamente, observaram teores de SS em torno de $15^{\circ} \mathrm{Brix}$, em diferentes cultivares de uvas Vitis labrusca, utilizadas para a elaboração de suco. Sob temperaturas altas, como no Vale do Submédio São Francisco, é esperado maior acúmulo de SS nas bagas (Lima \& Choudhury, 2007).

Outros autores relataram maior incremento no teor de SS, que atingiu de 16 a $22^{\circ} \mathrm{Brix}$, em cultivares como Romana, Niágara Rosada (Silva et al., 2008) e Corvina (Versari et al., 2001). Essas variações são justificadas pela influência que as condições locais, especialmente temperatura e insolação, e o manejo adotado no cultivo exercem sobre o metabolismo das uvas, que podem favorecer ou limitar o potencial genético da cultivar.

Como os açúcares solúveis totais (AST) são os principais constituintes dos $\mathrm{SS}$, essas variáveis apresentam respostas correspondentes, com crescente aumento durante a maturação (Coombe, 1987). As uvas da cultivar Isabel Precoce, aos 77 DAF, alcançaram teor de AST de 16,8 g por $100 \mathrm{~g}$, no primeiro semestre, e de 20,1 g por 100 g, no segundo (Figura 3). A 'BRS Cora', no momento da colheita no primeiro ciclo de produção de 2010, alcançou teor de 19,6 g por $100 \mathrm{~g}$, enquanto no segundo ciclo alcançou 17,7 g por $100 \mathrm{~g}$.

Em geral, cultivares de $V$. vinifera destinadas ao processamento, como Cabernet Sauvignon e Tannat, possuem maior potencial de produção de açúcares do que as uvas americanas ( $V$. labrusca). Esta característica, aliada à maior acidez residual, lhes permite alto potencial para vinificação(Perez-Magarino \& José, 2004; González-Neves et al., 2004; Abe et al., 2007). Contudo, a melhor qualidade do produto final depende do equilíbrio de um conjunto de compostos químicos. A relação entre açúcares e ácidos orgânicos sinaliza esse equilíbrio, de forma que autores como 
Ghosh et al. (2008) sugerem a aptidão de cultivares de uva para consumo da fruta fresca ou em processamento ou ambos, a partir da associação entre valores desses dois grupos de compostos.

O conhecimento das características físicas, relacionadas a rendimento, e das químicas, que definem o sabor e a adequação aos mercados de uva fresca ou processada, para condições particulares de cultivo, permite destacar atributos que podem ser específicos de uma região, em consequência de fatores ambientais, da cultura local associada à atividade produtiva, da infraestrutura disponível e da capacidade de investimento. Este conjunto contribui para a definição de estratégias comerciais que visem à oferta de um produto diferenciado.

\section{Conclusões}

1. O ponto ideal de colheita de uvas para elaboração de suco, nas condições do Vale do Submédio São Francisco, ocorre aos 77 dias após o início da frutificação, independentemente do período de produção, para a cultivar Isabel Precoce; para a BRS Cora, o ponto ideal ocorre aos 82 dias após o início da frutificação, no primeiro semestre, e é antecipado em quatro dias no segundo semestre.

2. Ambas as cultivares expressam potencial para elaboração de sucos de qualidade no Vale do Submédio São Francisco.

3. As uvas de 'BRS Cora' são as mais resistentes à compressão, mais ácidas e possuem maiores teores de SS e de AST do que as de 'Isabel Precoce'.

\section{Agradecimentos}

À Embrapa Semiárido, pelo apoio técnico-científico e financeiro; e ao Conselho Nacional de Desenvolvimento Científico e Tecnológico, por concessão de bolsa.

\section{Referências}

ABE, L.T.; DA MOTA, R.V.; LAJOLO, F.M.; GENOVESE, M.I. Compostos fenólicos e capacidade antioxidante de cultivares de uvas Vitis labrusca L. e Vitis vinifera L. Ciência e Tecnologia de Alimentos, v.27, p.394-400, 2007.

AOAC INTERNATIONAL. Official methods of analysis of the AOAC International. 11.ed. Washington: AOAC International, 1992. $1115 \mathrm{p}$.

CAMARGO, U.A.; MAIA, J.D.G. BRS Cora: nova cultivar de uva para suco, adaptada a climas tropicais. Bento Gonçalves: Embrapa
Uva e Vinho, 2004. 4p. (Embrapa Uva e Vinho. Comunicado técnico, 53).

CAMARGO, U.A.; PROTAS, J.F.S.; MELLO, L.M.R. de. Grape growing and processing in Brazil. Acta Horticulturae, v.785, p.51-53, 2008.

CELOTTI, E.; DE PRATI, G.C. The phenolic quality of red grapes at delivery: objective evaluation with colour measurements. South African Journal of Enology and Viticulture, v.26, p.75-82, 2005.

CIA, P.; BENATO, E.A.; VALENTINI, S.R. de T.; SANCHES, J.; PONZO, F.S.; FLÔRES, D.; TERRA, M.M. Atmosfera modificada e refrigeração para conservação pós-colheita de uva 'Niagara Rosada'. Pesquisa Agropecúaria Brasileira, v.45, p.1058-1065, 2010.

COOMBE, B.G. Distribution of solutes within the developing grape berry in relation to its morphology. American Journal of Enology and Viticulture, v.38, p.120-127, 1987.

GHOSH, S.N.; TARAI, R.; PAL, P.P. Performance of eight grape cultivars in laterite soil of West Bengal. Acta Horticulturae, v.785, p.73-77, 2008.

GIOVANNINI, E. Produção de uvas para vinho, suco e mesa. 2.ed. Porto Alegre: Renascença, 2005. 368p.

GONZÁLEZ-NEVES, G.; BARREIRO, L.; GIL, G.; FRANCO, J.; FERRER, M.; MOUTOUNET, M.; CARBONNEAU, A. Anthocyanic composition of Tannat grapes from the South Region of Uruguay. Analytica Chimica Acta, v.513, p.197-202, 2004.

GUERRA, C.C. (Ed.). Uva para processamento: pós-colheita. Brasília: Embrapa Informação Tecnológica; Bento Gonçalves: Embrapa Uva e Vinho, 2003. 67p. (Frutas do Brasil, 36).

INSTITUTO BRASILEIRO DE FRUTAS. Instituto Brasileiro de Frutas [home page]. 2011. Disponível em: $<$ http://www.ibraf.org. br/estatisticas/est_frutas.asp>. Acesso em: 24 nov. 2011.

LEVANTAMENTO sistemático da produção agrícola: pesquisa mensal de previsão e acompanhamento das safras agrícolas no ano civil. Rio de Janeiro: IBGE, 2011. 114p. Disponível em: < http:// www.ibge.gov.br/home/estatistica/indicadores/agropecuaria/lspa/ 1spa_201110.pdf>.Acesso em: 24 nov. 2011.

LIMA, M.A.C. de; CHOUDHURY, M.M. Características dos cachos de uva. In: LIMA, M.A.C. de (Ed.). Uva de mesa: pós-colheita. 2.ed. Brasília: Embrapa Informação Tecnológica; Petrolina: Embrapa Semi-Árido, 2007. p.21-30. (Série frutas do Brasil, 12).

MANFROI, V. Enologia. In: GIOVANINNI, E.; MANFROI, V. Viticultura e enologia: elaboração de grandes vinhos nos terroirs brasileiros. Bento Gonçalves: IFRS, 2009. 344p.

MASCARENHAS, R. de J.; SILVA, S. de M.; LOPES, J.D.; LIMA, M.A.C. de. Avaliação sensorial de uvas de mesa produzidas no Vale do São Francisco e comercializadas em João Pessoa - PB. Revista Brasileira de Fruticultura, v.32, p.993-1000, 2010.

MÉDIAS anuais da estação agrometeorológica de Bebedouro. Petrolina: Embrapa Semiárido, 2012. Disponível em: <http://www. cpatsa.embrapa.br:8080/servicos/dadosmet/ceb-anual.html $>$. Acesso em: 03 ago. 2012. 
MIGUEL, A.C.A.; DIAS, J.R.P.S.; ALBERTINI, S.; SPOTO, M.H.F. Pós-colheita de uva 'Itália' revestida com filmes à base de alginato de sódio e armazenada sob refrigeração. Ciência e Tecnologia de Alimentos, v.29, p.277-282, 2009.

MOTA, R.V. da; SOUSA, C.R. de; FAVERO, A.C.; SILVA, C.P.C. e; CARMO, E.L. do; FONSECA, A.R.; REGINA, M. de A.R. Produtividade e composição físico-química de bagas de cultivares de uva em distintos porta-enxertos. Pesquisa Agropecúaria Brasileira, v.44, p.576-582, 2009.

ORLANDO, T. das G.S.; PEDRO JÚNIOR, M.J.; SANTOS, A.O.; HERNANDES, J.L. Comportamento das cultivares Cabernet Sauvignon e Syrah em diferentes porta-enxertos. Ciência e Agrotecnologia, v.32, p.749-755, 2008.

PEREIRA, G.E.; LIMA, L.C. de O.; REGINA, M. de A.; ROSIER, J.-P.; FERRAZ, V.; MOURÃO JUNIOR, M. Avaliação do potencial de cinco cultivares de videiras americanas para sucos de uva no sul de Minas Gerais. Ciência e Agrotecnologia, v.32, p.1531-1537, 2008.

PEREZ-MAGARINO, S.; JOSÉ, M.L.G.S. Evolution of flavanols, anthocyanins, and their derivatives during the aging of red wines elaborated from grapes harvested at different stages of ripening. Journal of Agricultural and Food Chemistry, v.52, p.1181-1189, 2004.

SATO, A.J.; SILVA, B.J. da; BERTOLUCCI, R.; CARIELO, M.; GUIRAUD, C.; FONSECA, I.C. de B.; ROBERTO, S.R. Evolução da maturação e características físico-químicas de uvas da cultivar Isabel sobre diferentes porta-enxertos na região norte do Paraná. Semina: Ciências Agrárias, v.30, p.11-20, 2009.
SATO, A.J.; SILVA, B.J. da; SANTOS, C.E. dos; BERTOLUCCI, R.; SANTOS, R. dos; CARIELO, M.; GUIRAUD, C.; FONSECA, I.C. de; ROBERTO, S.R. Características físico-químicas e produtivas das uvas 'Isabel' e 'BRS-Rúbea' sobre diferentes porta-enxertos na região norte do Paraná. Revista Brasileira de Fruticultura, v.30, p.553-556, 2008.

SILVA, F.C.C. da; VIANA, A.P.; SILVA, M.G.O. da; OLIVEIRA, J.G. de; GOMES FILHO, A. Caracterização química e determinação dos estádios fenológicos de variedades de videiras cultivadas no Norte Fluminense. Revista Brasileira de Fruticultura, v.30, p.38-42, 2008.

SOARES, M.; WELTER, L.; KUSKOSKI, E.M.; GONZAGA, L.; FETT, R. Compostos fenólicos e atividade antioxidante da casca de uvas Niágara e Isabel. Revista Brasileira de Fruticultura, v.30, p.59-64, 2008.

STEFFENS, C.A.; AMARANTE, C.V.T. do; CHECHI, R.; SILVEIRA, J.P.G.; BRACKMANN, A. Aplicação pré-colheita de reguladores vegetais visando retardar a maturação de ameixas 'Laetitia'. Ciência Rural, v.39, p.1369-1373, 2009.

VERSARI, A.; PARPINELLO, G.P.; TORNIELLI, G.B.; FERRARINI, R.; GIULIVO, C. Stilbene compounds and stilbene synthase expression during ripening, wilting, and UV treatment in grape cv. Corvina. Journal of Agricultural and Food Chemistry, v.49, p.5531-5536, 2001.

YEMN, E.W.; WILLIS, A.J. The estimation of carbohydrate in plant extracts by anthrone. The Biochemical Journal, v.57, p.504-514, 1954.

Recebido em 29 de março de 2012 e aprovado em 27 de julho de 2012 